\title{
HISTÓRIA DA EDUCAÇÃO: SENSIBILIDADES, PATRIMÔNIO E CULTURA ESCRITA
}

\author{
Luciane Sgarbi Santos Grazziotin ${ }^{1}$ \\ Eduardo Cristiano Hass da Silva²
}

No ano de 2018, o $24^{\circ}$ Encontro da ASPHE, organizado pela Associação Sul-Rio-Grandense de Pesquisadores em História da Educação, discutiu o tema "História da Educação: sensibilidades, patrimônio e cultura escrita"3. Atentando para as recentes temáticas que vêm sendo desenvolvidas no âmbito históricoeducativo, o encontro reuniu pesquisadores e pesquisadoras a partir desses três eixos.

\footnotetext{
${ }^{1}$ Universidade do Vale dos Sinos (UNISINOS) São Leopoldo/RS, Brasil.

2 Universidade do Vale dos Sinos (UNISINOS), São Leopoldo/RS, Brasil.

$3 \mathrm{O} 24^{\circ}$ Encontro da ASPHE ocorreu nas dependências da Universidade do Vale do Rio dos Sinos (UNISINOS). Os trabalhos apresentados foram publicados na forma de anais e estão disponíveis online. Ver: GRAZZIOTIN; SILVA; DIAS; BARROS (2018). Este dossiê reúne parte das conferências e mesas temáticas que ocorreram no evento.
} 
Ao propor uma introdução ao tema da História Cultural, a historiadora Sandra Jatahy Pesavento (2005), com base em teóricos que fundamentam a discussão por ela tematizada - com destaque para Stone (1981), Certeau (1982), Chartier (1988, 1991), White (1994), entre outros presentes em sua obra -, fez um resumo dos principais conceitos norteadores de um conjunto de mudanças epistemológicas que proporcionaram um novo olhar a historiadores e historiadoras. A entrada em cena desses conceitos reorientou a escrita da história; nesse sentido, destacamos: representação, imaginário, narrativa, ficção e sensibilidades - todos esses presentes, de uma forma ou de outra, nos textos que compõem o dossiê que ora apresentamos.

Por sensibilidades, a autora entende o núcleo primário de percepção e tradução das experiências humanas no mundo e, também, as formas como os indivíduos e grupos se dão a perceber. As "sensibilidades se exprimem em atos, em ritos, em palavras e imagens, em objetos da vida material, em materialidades do espaço construído" (PESAVENTO, 2005, p. 34). Essa definição de sensibilidade, assim como outras, são apresentadas e discutidas nos artigos aqui presentes.

Como forma de introduzir a ideia de patrimônio, baseamo-nos no conceito de Françoise Choay (2006). O autor afirma que patrimônio histórico "é uma expressão que designa um bem destinado ao usufruto de uma comunidade que se ampliou a dimensões planetárias, constituído pela acumulação contínua de uma diversidade de objetos que se congregam por seu passado comum: obras primas das belas-artes e das artes aplicadas, trabalhos e produtos de todos os saberes e savoir-faire dos seres humanos" (CHOAY, 2006, p. 11).

Após a definição, o autor continua a reflexão afirmando que, em nossa sociedade - líquida, flexível e errante, que é constantemente transformada pela globalização e pela mobilidade de seu presente -, "patrimônio histórico" tornou-se uma palavra emblemática das tribos midiáticas, remetendo a uma instituição e a uma mentalidade. (CHOAY, 2006).

Assim como as sensibilidades e as discussões sobre patrimônio, outra 
temática cara a historiadores e historiadoras tem se dado em torno da Cultura Escrita, presente, sobretudo, nas discussões de historiadores como Roger Chartier (1994, 2002) e Robert Darnton (1990). A partir da análise de textos produzidos durante o Antigo Regime, Chartier (2002) analisa a materialidade dos livros e as formas de apropriação da leitura, concluindo que "a leitura não é somente uma operação abstrata de intelecção: ela é uso do corpo, inscrição em um espaço, relação consigo ou com o outro" (p. 70). Para Darnton, os objetos impressos devem ser compreendidos como um todo, que surge e se difunde pela sociedade. Esses impressos possuem um 'ciclo de vida', marcado pelos diferentes sujeitos que dele fazem parte, como autores, editores, impressores, distribuidores, vendedores e leitores.

Sendo assim, os textos reunidos neste dossiê permitem pensar como os temas sensibilidades, patrimônio e cultura escrita têm sido desenvolvidos nas pesquisas que se inserem no campo da História da Educação. Para isso, estruturamos uma ordem de textos, construindo, por meio deles, uma narrativa sobre a temática abordada. Abrindo a discussão, o texto "Pesquisas sobre a educação dos sentidos e das sensibilidades na história da educação: algumas indicações teórico-metodológicas", de Marcus Aurélio Taborda de Oliveira, centra-se nos pressupostos teórico-metodológicos que sustentam as pesquisas dos sentidos e das sensibilidades em História da Educação. Compreendendo a educação de forma dialógica, Taborda de Oliveira mobiliza autores que refletem sobre a experiência e a materialidade da vida, bem como sobre a corporalidade na sua expressão mais plena (BAKHTIN, 1999, 2011). Entendendo que "praticamente qualquer tipo de material se presta ao estudo histórico dos sentidos e das sensibilidades", o autor foca-se no uso da imprensa como suporte documental, tanto em sua dimensão textual quanto imagética. O texto finaliza oferecendo alguns exemplos de trabalhos desenvolvidos nesse âmbito de estudos.

A partir do exame discursivo de entrevistas realizadas sob a ótica da História Oral, de periódicos escolares, de fotografias e de plantas de edificações 
escolares, o segundo texto, de Lucas Costa Grimaldi e Dóris Bittencourt Almeida, intitulado "Narrativas do espaço habitado: sensibilidades no estudo dos prédios escolares de Porto Alegre/RS (1940/1980)”, cartografa sensibilidades sobre o espaço vivido por estudantes porto-alegrenses durante o processo de escolarização. O artigo tem como recorte temporal o período entre 1920-1980 e, nessa temporalidade, analisa as edificações das seguintes instituições: Colégio Marista Rosário, Colégio Anchieta, Colégio Americano e Colégio Farroupilha de Porto Alegre. Defendendo que os espaços escolares habitados adquirem um lugar de destaque na memória de antigos estudantes, os autores entendem que as memórias desse espaço trazem evidências para compreender a arquitetura escolar como um elemento central durante a escolarização.

Na sequência, entendendo cadernos de usos não escolares como parte do patrimônio do escrito, o terceiro texto, de Vania Grim Thies, intitulado "Patrimônio do escrito: cadernos de usos não escolares e as contribuições para a cultura escrita”, analisa um total de 55 cadernos que, a partir do seu conteúdo, receberam dez diferentes classificações: cadernos de celebrações religiosas, cadernos de receita, cadernos de recordações, cadernos de versos e poesias, cadernos questionários, cadernos de músicas, cadernos de canções, cadernos de contas, cadernos de diários pessoais e cadernos de cartões. A autora defende que esses materiais contribuem para a construção do conhecimento históricoeducativo, uma vez que comportam uma multiplicidade de registros, tais como informações sobre o cotidiano, contas, memórias, entre outros.

É também sobre a cultura escrita que se debruça Meritxell SimonMartin, em "La educación epistolar: los intercambios de cartas entre mujeres burguesas como fuente de desarrollo personal en la Inglaterra Victoriana”. A partir do conceito de 'educação epistolar', a autora pesquisa a correspondência pessoal de três mulheres burguesas inglesas, explorando a carta como um instrumento educacional. A análise das cartas permite identificar os acordos entre as mulheres e seus pretendentes e familiares. As escritas femininas estão 
presentes também no artigo de Maria Celi Chaves Vasconcelos, intitulado "Escritas femininas na casa oitocentista: memórias sobre o diário da Viscondessa de Arcozelo". A partir do Diário de Lembranças da Viscondessa, a autora procura recompor os cenários nos quais ela realizava suas escritas pessoais e, por meio da correspondência, verifica como essa mulher do século XIX geria suas propriedades e seus pertences, ultrapassando o que era esperado de uma mulher educada para ser esposa e mãe. Assim, a casa oitocentista emerge como o cenário das escritas realizadas no diário.

Encerramos o conjunto de artigos que compõem o dossiê temático com o texto "Eu te dedico: História, Educação e Sensibilidades nas dedicatórias de livros de um professor catarinense (1940-1980)", de autoria de Maria Teresa Santos Cunha, uma vez que, com suas reflexões, a autora faz uma primorosa costura entre os conceitos de sensibilidades, patrimônio e cultura escrita, articulando esses três eixos de análise aqui abordados. Nesse sentido, Cunha inventaria e analisa as dedicatórias presentes em livros do professor catarinense Victor Márcio Konder (1920-2005).

A partir do entendimento das dedicatórias, o artigo traça circuitos de sociabilidades, ao mesmo tempo em que identifica elementos relacionados à circulação, à posse e ao consumo de livros. Entendendo a história das sensibilidades conectada à História da Educação, na qual os livros são tomados como parte patrimônio histórico-educativo, o texto encerra, portanto, a tessitura entre os temas aqui tomados como eixo.

Inspirados em Walter Benjamin (2012), finalizamos esta apresentação com o entendimento de que as discussões históricas propostas pelos artigos aqui presentes compreendem, em alguma medida, o que o autor chama de "coisas refinadas e espirituais". Elas fazem parte da luta de classe; porém, "vivem essa luta sob a forma da confiança, da coragem, do humor, da astúcia, da firmeza, e atuam retroativamente até os tempos mais remotos. Elas questionarão sempre cada vitória dos dominadores." (p. 243) Na continuidade da reflexão proposta por Benjamin, entendemos que, "assim como as flores dirigem sua corola para o 
sol, o passado, graças a um misterioso heliotropismo, anseia por dirigir-se para o sol que se levanta no céu da história” (p. 243).

\section{REFERÊNCIAS}

BENJAMIN, Walter. Magia, técnica, arte e política: ensaios sobre literatura e história da cultura. São Paulo: Brasiliense, 2012.

CERTEAU, Michel de. A escrita da História. Rio de Janeiro: Forense Universitária, 1982.

CHARTIER, Roger. A História Cultural: entre práticas e representações. Lisboa: DIFEL, 1988.

CHARTIER, Roger. O mundo como representação. Estudos avançados, 11(5), São Paulo, 1991.

CHARTIER, Roger. A ordem dos livros: leitores, autores e bibliotecas na Europa entre os séculos XIV e XVIII. Brasília: Editora Universidade de Brasília, 1994 .

CHARTIER, Roger. À Beira da Falésia: a história entre incertezas e inquietações. Porto Alegre: Ed. Universidade/UFRGS, 2002.

CHOAY, Françoise. A alegoria do patrimônio. São Paulo, Ed. UNESP, 2006.

DARTON, Robert. O Beijo de Lamourette - Mídia, cultura e revolução.

Tradução Denise Bottman. São Paulo: Companhia das Letras, 1990.

GRAZZIOTIN, Luciane Sgarbi Santos; SILVA, Eduardo Cristiano Hass da;

DIAS, Dafne Regina de Oliveira; BARROS, Tainá Martins de. (Orgs.). Anais do $2^{\circ}$ Encontro da Associação Sul-rio-grandense de Pesquisadores em História da Educação - "História da Educação: Sensibilidades, patrimônio e cultura escrita, 2018. Disponível em:

https://drive.google.com/file/d/1yulmkddBr8 E5xSh5R9QAWFDzrnPwKiw/vi ew.

PESAVENTO, Sandra Jatahy. História \& História Cultural. Belo Horizonte: Autêntica, 2005 .

STONE, Lawrence. De revival of narrative. The past and present. Boston: Routledge \& Kegan Paul. 1981. 
WHITE, Hayden. Meta-história: a imaginação histórica no século XIX. São Paulo: EDUSP, 1992.

LUCIANE SGARBI SANTOS GRAZZIOTIN é doutora em Educação, ênfase em História da Educação pela Pontifícia Universidade Católica/RS (PUCRS)(2008). Fez doutorado-sanduíche na Universidade Clássica de Lisboa (2007) e pósdoutorado na Universidad Nacional de Educación a Distancia (Uned) em Madri (bolsa Capes, 2017). Fez Mestrado em Ciências (1991) e graduação em Biologia - Licenciatura. Atualmente é professora e pesquisadora na graduação e no Programa de Pós-Graduação em Educação da Escola de Humanidades da Universidade do Vale do Rio dos Sinos (Unisinos).

E-mail: lusgarbi@terra.com.br

(i) http://orcid.org/0000-0001-5648-3855

EDUARDO CRISTIANO HASS DA SILVA é doutorando em educação pela Universidade do Vale do Rio dos Sinos (Unisinos). Licenciado, Bacharel e Mestre em História pela Pontifícia Universidade Católica do Rio Grande do Sul.

E-mail: eduardohass.he@gmail.com

(iD) http://orcid.org/0000-0002-3906-5448

Recebido em: 17 de outubro de 2019

Aprovado em: 13 de janeiro de 2020

Revista História da Educação - RHE

Associação Sul-Rio-Grandense de Pesquisadores em História da Educação - Asphe Artigo de acesso aberto distribuído nos termos de licença Creative Commons. 